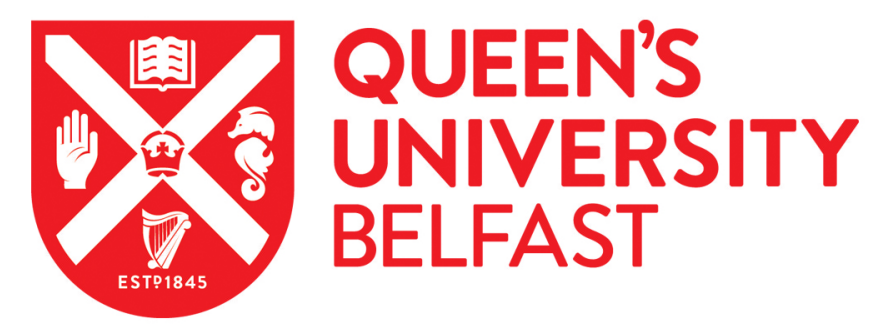

\title{
Between ethos and practice: Are Ireland's new multi-denominational primary schools equal and inclusive?
}

Faas, D., Smith, A., \& Darmody, M. (2018). Between ethos and practice: Are Ireland's new multi-denominational primary schools equal and inclusive? Compare: A Journal of Comparative and International Education. https://doi.org/10.1080/03057925.2018.1441704

Published in:

Compare: A Journal of Comparative and International Education

Document Version:

Peer reviewed version

Queen's University Belfast - Research Portal:

Link to publication record in Queen's University Belfast Research Portal

Publisher rights

(C) 2018 British Association for International and Comparative Education.

This work is made available online in accordance with the publisher's policies. Please refer to any applicable terms of use of the publisher.

\section{General rights}

Copyright for the publications made accessible via the Queen's University Belfast Research Portal is retained by the author(s) and / or other copyright owners and it is a condition of accessing these publications that users recognise and abide by the legal requirements associated with these rights.

Take down policy

The Research Portal is Queen's institutional repository that provides access to Queen's research output. Every effort has been made to ensure that content in the Research Portal does not infringe any person's rights, or applicable UK laws. If you discover content in the Research Portal that you believe breaches copyright or violates any law, please contact openaccess@qub.ac.uk. 
This is an Accepted Manuscript of an article published by Taylor and Francis in Compare: A Journal of Comparative and International Education on 28/02/2018, available online: https://www.tandfonline.com/doi/full/10.1080/03057925.2018.1441704

\section{Between ethos and practice: Are Ireland's new multi-denominational primary schools equal and inclusive?}

\section{Abstract}

This article explores the ethos of multi-denominational primary schools in the context of increasing cultural and religious diversity in the Republic of Ireland. In particular, it investigates how the official ethos is played out in day-to-day school interactions. The mixed-methods study draws on data collected from 11 community national schools focussing on the perspectives of principals, teachers and pupils. The data indicates while schools' formal ethos sets out guiding principles and standards, a closer look reveals the specific identity of each individual school within the broader formal framework. The article presents a new perspective on school ethos research by exploring the extent to which it guides the promotion of diversity and tolerance in a multi-faith context. While the study is carried out in Ireland, it is also of interest to other jurisdictions where schools are faced with increasing religious diversity among their student population.

Key words: multi-denominational primary schools, school identity, ethos, Ireland. 


\section{Introduction}

Ireland has seen rapid social change in recent years and there is currently a mismatch between a largely denominational (Catholic) primary education system and increasing ethno-cultural and religious diversity. Considering these changes, there is now a variety of beliefs among children in Irish schools, yet over 95 per cent of primary schools are denominational. Schools have a crucial role to play in terms of social integration and inclusion. While a small amount of research has been conducted comparing Catholic denominational and multi-denominational Educate Together schools (see Darmody, Smyth and McCoy 2012; McGovern and Devine 2016), this is the first empirical study exploring the views of principals, teachers and pupils in the new state-run multi-denominational community national school (CNS) model in Ireland (see also Faas et al. 2018).

Irish census figures from 2016 show that while the number of people identifying as Catholic remains high $(78.3 \%)$ there has also been a considerable increase in the 'no religion' category (from $5.6 \%$ in 2011 to $9.8 \%$ in 2016, see Central Statistics Office 2017). At the same time, there has been an overall decrease in religiosity (attending services) among the population according to the European Values Study (Breen and Reynolds 2011). Large-scale immigration into Ireland has introduced further diversity to the jurisdiction which impacts education. Religious education (RE) permeates the school day, especially in the primary school sector. While parents can opt their child out of RE, this may result in highlighting differences between children, something parents may wish to avoid (Smyth and Darmody 2011). Previous research has recognised the role of the school as an important site for learning tolerance of diversity by providing children with opportunities for various forms of interaction (Smyth, Lyons and Darmody 2013; Darmody and Smyth 2017) as well as for identity formation (see Faas 2010). Educational policy in Ireland has addressed the need to support diversity by devising intercultural education guidelines focusing on equality and human rights. A 'learning about religion' approach is evident in the Intercultural Education guidelines for primary schools issued by the National 
Council of Curriculum and Assessment (NCCA) in 2006. It remains unclear, however, how successful schools have been in implementing the recommendations.

The disparity between the dominance of Catholic schools which emphasise faith formation and the increasingly culturally diverse population may increase the potential for tensions between home and school over children's faith and character development as teachers and parents might not share the same culture or values (Darmody, Lyons and Smyth 2016). The issue of the role of religion (such as sacramental preparation and faith formation) in state-funded schools is of growing political and educational importance in Ireland, as is the question of various models of moral and ethical education.

Over the years, debate concerning the role of religion in publicly funded schools has intensified in Ireland and elsewhere in Europe (McKinney 2011). This is due to a number of factors, including support for the continuation and extension of faith-based schooling (despite secularisation of most European societies) in some jurisdictions, and increasing diversity due to immigration. In order to accommodate diverse needs of their population, countries across Europe have taken different approaches to RE. While some countries are extending the number of faith schools (e.g. UK), others have opted for the removal of religion from the formal educational system (e.g. France, Slovenia), or have made RE an option (e.g. Poland) (see Faas, Darmody and Sokolowska 2016).

This article addresses the following research questions: To what extent does the formal/lived ethos of CNS support the promotion of diversity, tolerance and integration? How do CNS differ in the ways they translate the school ethos into everyday practice? What role does religion and RE play in this new type of primary school? 


\section{School ethos, identity and integration}

The empirical literature on school ethos is wide and it is beyond the scope of this article to consider all the components (the concept of ethos is discussed in the next section). The focus of this article is on the extent CNS meet their official ethos of being equal and inclusive, and how this ethos guides the promotion of diversity and tolerance in a multi-faith school context. Often the official documents and mission statements of a school do not necessarily translate to practice (Donnelly 1999). In Ireland, the patronage system means schools come under ownership of groups with a particular ethos. Within schools with similar ethos (such as denominational schools), however, the ways that ethos is lived out may differ. Sai (2018) found varying ways of practicing a denominational ethos in Dublin's Muslim primary schools, including differences in approaching prayer, attitudes towards the hijab and the use of language. Institutions with a Catholic ethos, who have pupils from non-Catholic or no-faith backgrounds, also have varying levels and ways of promoting inclusion (Smyth and Darmody 2011).

Schools are often turned to as sites of promoting cohesion and integration. Practice within the school can influence how far inclusion and equality are met. Integrative environments, that seek to include migrant young people, can foster positive relationships with society (Faas 2007; Faas 2010), while a 'celebration of diversity' approach may highlight difference and serve to exclude migrant student's experiences (Bryan and Bracken 2011).

External factors can also impact on a school practising its ethos. In schools with a multicultural approach, Wilson (2014) found that while parents were largely supportive, some acknowledged their own limits in accommodating diversity. This exposed hierarchical conceptions of belonging, resulting in tensions between the official ethos and everyday interactions of parents and wider community. Hemming (2011) found that children's learning within school, such as how to interact with diversity or their intercultural education, was sometimes challenged by home values and parental influence. 


\section{Conceptual framework}

The concept of ethos can be contested due to the difficulties involved in defining it, considering it to be 'intangible, obscure and impenetrable' (Furlong 2000, 59). Over time, various educationalists have endeavoured to uncover the nature of ethos, seeing it as shaping the dispositions, values and attitudes of persons in a field where tradition plays an important role (McLaughlin 2005). This may be related to the concept of 'institutional habitus' (Reay, David and Ball 2001), a re-elaboration of Bourdieu's concept of habitus, the depositions underlying practices and internalised beliefs determined by one's background (Bourdieu 1993). Institutional habitus is the influence of attending a particular institution on an individual's practice (Reay et al. 2001). Although developed through work on students in tertiary education, the concept can assist understanding of the ways institutions influence students' experiences and perceptions of school. While Reay et al (2001) do not consider this in line with ethos, it is an interesting concept to consider when discussing multi-denominational, inclusive schooling, from the perspective of how values of equality may be transmitted to pupils, as well as influencing staff behaviour. This becomes important when considering ethos and can also facilitate understanding of people's action in the field. For example, according to Munn (2008), 'ethos affects our practice' and helps understand why individuals act in specific ways, and the variation of action between schools. Bragg and Manchester (2011) argue that marketization of education has resulted in the perceived need for schools to develop distinct identities, of which ethos plays a part, to compete for and attract 'customers'.

School ethos can also be associated with school effectiveness (Hargreaves and Hopkins 1991) as well as having an impact on various school processes (Monahan 2000). The complexity of the concept is also evident in a description given by Bragg and Manchester (2011) who see ethos consisting of various elements; it embodies values and a vision of society; is simultaneously official and unofficial; is shaped by everyday social interactions and relationships; is intangible and experiential rather than being easily 
described or articulated; can emerge from material and social aspects of the environment, and finally, is continuously negotiated by students and teachers who are active agents in developing and defining school ethos. At times, according to Donnelly (1999), the official school ethos, as described in school documentation or defined by school authorities, can differ considerably from the ethos which emerges from the dispositions, social interactions and behaviour of people in the school.

One aspect of school ethos is its religious identity (Avram and Dronkers 2013). In many European countries, denominational schools are non-governmental schools, although in a number of jurisdictions denominational schools can be state-funded (Smyth et al. 2013). The identity of denominational schools can be expressed in a number of ways, including their ownership, names, admission criteria and curriculum. Their legal status tends to vary across European societies, depending on historical legacies and governance.

The advocates of denominational schools often refer to freedom of choice. In an exploration of the variation within the Irish primary school sector, Darmody et al (2012) found parents with a specific religious background may seek out schools with an ethos corresponding to their beliefs. Likewise, denominational schools may prefer to admit students who share the same beliefs and values promoted by their ethos. Denominational schools can be seen as important for sustaining religion, culture, identity and language, and for maintaining continuity of belief between home and school (Cohen-Zada 2006). Others, however, view denominational schools as problematic to social cohesion (O'Toole 2015). There have been efforts made by some schools to challenge the notion that denominational schools are socially divisive through engaging with the local community who may be outside of the faith characterised in the school (see Breen 2009). Ferrari and Pastorelli (2010) argue that schools are not only public spaces but are public institutions and as such should be religiously neutral. Introduction of multi-denominational or inter-denominational schools is an attempt to cater for culturally and religiously diverse student populations. While it is difficult to offer satisfactory 
definitions of the concept of ethos, it is important in understanding general social processes in schools and to show the extent to which practices support official mission statements.

\section{Irish Primary School Sector}

Compared to other European countries, the Irish primary school sector is diverse in terms of types of schools and patronage. This variation is unevenly distributed (see Table 1); denominational schools possessing a religious ethos are dominant, with $89.8 \%$ of these being Catholic. The remaining schools are inter-denominational (providing an inter-Christian ethos) and multi-denominational, accommodating children from all faiths and none.

Table 1: Primary schools in Ireland in 2017

\begin{tabular}{lcc}
\hline \multicolumn{1}{c}{ School type } & Number & Percentage \\
\hline Denominational & $\mathbf{3 , 0 0 4}$ & $\mathbf{9 6}$ \\
Catholic (including Gaelscoileanna) & 2,808 & 89.8 \\
Church of Ireland & 175 & 5.6 \\
Other Christian & 17 & 0.5 \\
Muslim & 3 & 0.1 \\
Jewish & 1 & 0.03 \\
Multi-denominational & $\mathbf{1 0 8}$ & $\mathbf{3 . 4}$ \\
Educate Together (ET) & 81 & 2.6 \\
Community National Schools (CNS) & 12 & 0.4 \\
Irish medium (Gaelscoileanna) & 10 & 0.3 \\
Other & 5 & 0.2 \\
Inter-denominational (Gaelscoileanna) & $\mathbf{1 8}$ & $\mathbf{0 . 6}$ \\
$\quad$ Total & $\mathbf{3 , 1 3 0}$ & $\mathbf{1 0 0}$ \\
\hline
\end{tabular}

Source: Adapted from www.education.ie 
While the majority of primary schools in Ireland are privately owned and supported by the patron or owners, the state contributes the majority of building and running costs. Primary schools provide education for children from the ages of four to eleven or twelve years and all follow the 1999 curriculum, with the exception of RE. The responsibility for RE lies with school patrons and is delivered through a 'patrons programme'. Subsequently, approaches to RE vary between schools. Nearly all primary schools in Ireland are denominational in their pupil intake and management. Nevertheless, many denominational schools admit children from different belief backgrounds including no-faith children (Smyth et al. 2013). In Catholic denominational schools, pupils say daily prayers and are prepared together for the sacraments. Opt-outs from religious instruction are possible and some schools manage to accommodate non-Catholic children, however, for many schools there are limited alternatives and pupils are often kept in class working on other tasks (Darmody and Smyth 2017). This presents challenges as the ethnic and religious diversity among the pupil population in the primary school sector in Ireland grows.

A notable exception has been the establishment and growth of multi-denominational schools, of which there are now two types. The difference between these schools is largely how they approach religion. Multi-denominational schools tend to have higher proportions of children from professional, managerial and technical backgrounds than Catholic denominational schools, more pupils with a migrant background, as well as a higher number of non-Catholic and no-faith pupils (Darmody et al. 2012). The first type of multi-denominational school, Educate Together (ET), was set up in 1978 due to parental demand to provide an alternative to the dominant Catholic denominational primary system. ET schools are now under the patronage of a charity body of the same name and are the fastest growing school type at primary level. At present, there are 82 ET primary schools, mostly in urban areas. The ethos of ET schools stipulates equal respect for children from all social, cultural and 
religious backgrounds. This is represented through the specific ethics curriculum, which comprises ethics and values with a comparative view of world religions where pupils learn about religion instead of being instructed in religion. Unlike in Catholic denominational schools, pupils wear no school uniforms, address teachers informally using first names, and sacramental preparation for Catholic children takes place outside regular school hours instead of during school time. Schools are also mostly named after their geographical location rather than after saints.

In 2008 , the Irish state established and became patron, for the first time, of multi-denominational community national schools (CNS). These are run by the Education and Training Boards (ETB) and combine elements from the Catholic denominational and ET schools; for example, pupils wear a school uniform and they address their teachers formally. Unlike in ET schools, however, pupils in CNS learn about religion as well as from religion through what is referred to as 'belief-nurturing' whereby children are encouraged within class to discuss and share their own experiences of their home beliefs. In most CNS, sacramental preparation is also offered as part of the school day to Catholic children unlike ET schools (this is dealt with in greater detail in the findings section). At the time of fieldwork, there were 11 CNS in Ireland. One more has since been established (September 2017) which was not part of this study. Of the 12 CNS, nine are located in urban areas, with three in rural Ireland. Access to the various different school types in Ireland is generally limited by region with greater variety available in large urban centres (the three Muslim schools and one Jewish school listed in Table 1 are both in Dublin), at least in principle ${ }^{1}$. This creates a situation where many pupils attend schools that do not reflect their belief background (Faas et al. 2016).

\section{Methodology}

This study employed a mixed-methods approach consisting of principal questionnaires, semistructured interviews with principals and teachers, and pupil focus group discussions (see Table 2). 
Questionnaires explored the schools' approach to RE, diversity and school ethos, while in-depth interviews with principals and teachers explored the complexity of practices at school level. The interviews lasted up to one hour each. In six out of the 11 schools (who had a fifth class [ages 10-11] or higher) pupil focus groups were conducted to gain the perspectives of children. Fifth class pupils were selected as they have more experience of school. Themes discussed with pupils centred on the school day, RE and friendships. An interview guide was also used for these groups. The focus groups took place in a quiet location on the school premises where the children would normally be taught and lasted for 40 minutes on average. Focus groups consisted of four to five pupils each with at least two groups in each school. The focus groups were arranged around 'belief-specific' groups: 'Catholic', 'Christian', 'Muslim', 'No Religion' and 'Hindu'. It was expected that as part of a homogeneous group the children may have been more forthcoming in expressing their views about beliefs.

Table 2: Dataset

Principal Survey
11

Interviews
Principal interviews
Teacher Interviews
Pupil focus groups
Catholic
Christian
Muslim
No Religion
Hindu

11

21

6

5

3

2

1

49

This article is based primarily on interview data from teachers and principals, although data from the pupil focus groups is also referred to. The main data set is supplemented by informal observations which happened ad hoc while walking on the school premises, for example along corridors or in the playground. Full ethical clearance was sought from the university ethics committee. All schools were 
invited and agreed to take part in the study. Interviews and focus groups were recorded and analysed in the first instance for themes relating to RE and managing diversity. All individuals were anonymised in this article using pseudonyms with schools identified as either urban (U) or rural (R). Both researchers conducting the study are relatively young, with extensive expertise in conducting mixedmethods research in various educational contexts. In terms of positionality, this in-depth knowledge helped to build trust and rapport with interviewees.

\section{School ethos in community national schools (CNS)}

Official documents ${ }^{2}$ state CNS are 'committed to a spirit of inclusion and equality' valuing and respecting all children and their families. It is their mission 'to provide a model of primary education that reflects Ireland in the $21^{\text {st }}$ Century', within a 'setting of diversity and inclusion'. Furthermore, they aim to cater for 'the academic, physical, social, emotional and spiritual needs of the children within the school day'. The CNS model also states that 'nurturing the religions/beliefs of each child is integral to the daily routine of the school'.

In the questionnaire, principals were asked in open-ended questions to describe the ethos or characteristic spirit of their school and to provide examples of ways they ensured this. Principals offered a variety of ways their school develops or maintains its ethos. Common across all 11 schools was the recognition of children's beliefs, admissions policies and welcoming ceremonies for junior infants where faith leaders were invited. Some schools mentioned 'intercultural days', and celebration of festivals. One school referred explicitly to the 'hidden curriculum' whereby the inclusive, multicultural and equality-based nature of the school is reflected in the use of resources. Later observation and interviews revealed most schools shared a similar 'hidden curriculum', with resources and displays promoting the diversity of the school, including 'beliefs walls' and events calendars. 
Enrolment policies are one way a school upholds its ethos (Figure 1). From the principal questionnaire the most common criteria for admitting pupils to CNS is the 'sibling rule' (72.7\%), admitting a child who has an older sibling in the school. After this, residency in the local area and date of application are most common, both with $45.5 \%$ of schools stating this is 'often or always' considered upon application. One school also stated they enforced an 'oldest first' rule, while another required parental acceptance of its 'equality policy'.

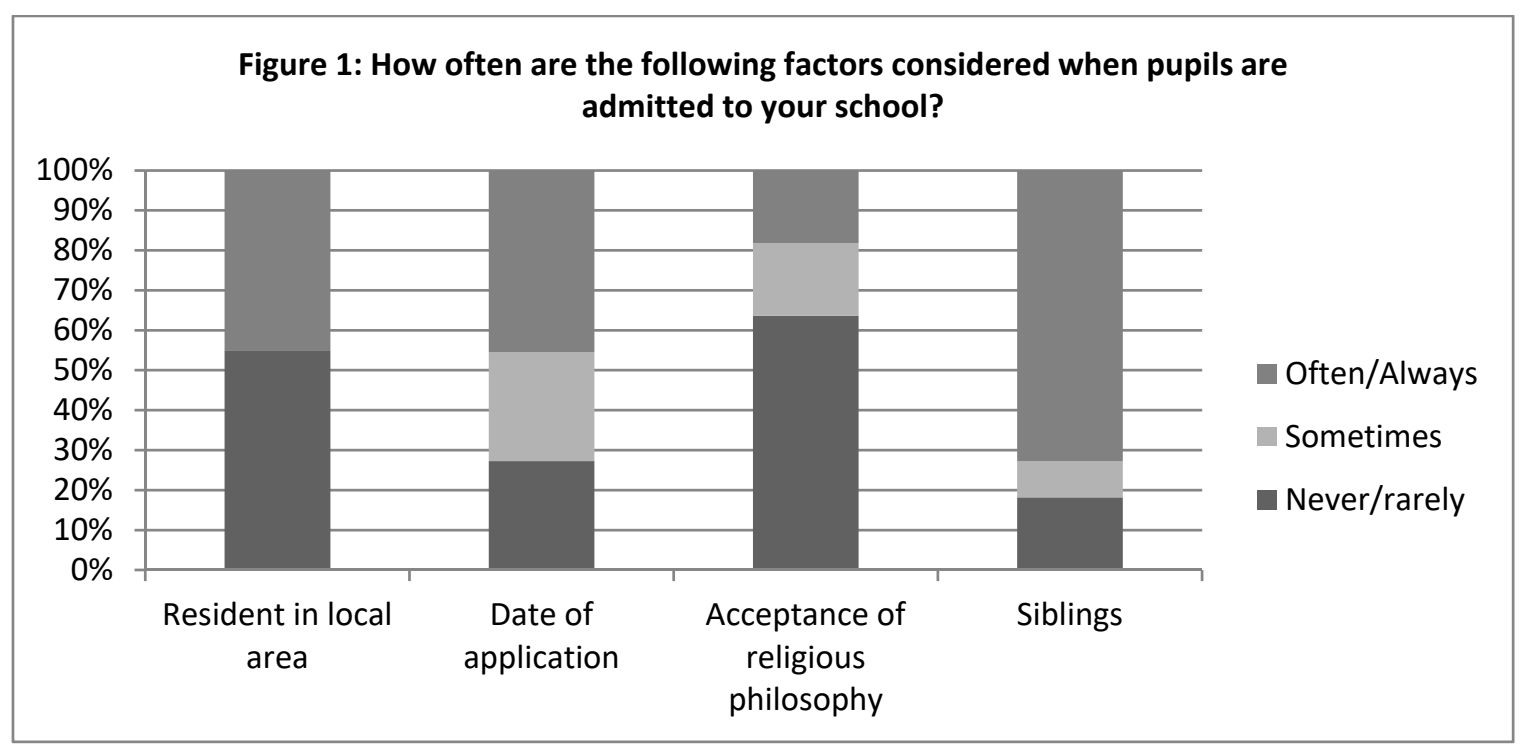

Schools stated they welcomed children from all backgrounds. The responses to the questionnaire showed schools had a diverse intake of pupils, although 'Catholic' made up the largest single faith group in $81.8 \%$ of schools. 'Other Christian' made up the second-largest faith group (45.5\%) while 'no religion' was the second largest in $36.4 \%$ of schools. The majority of schools $(60 \%)$ indicated that Irish students made up more than $50 \%$ of the pupil population. Only one school stated they had less than $25 \%$ Irish pupils in the school.

Information provided by the questionnaire was followed up with interviews with principals and teachers. In these interviews, the official ethos statements were often referred back to: 
This school includes all faiths and none - it's inclusive. GMGY [The 'Goodness Me Goodness You' RE programme] promotes that, the programme is very child-centred, and it's faith nurturing as opposed to faith formation. (Ann, Teacher, R)

A common theme arising in the interviews was 'respecting beliefs' and an emphasis on openness as long as it was respectful of all beliefs. Teachers described facilitating discussions between children who may have shown disrespect to other beliefs and values, for example through exclamations about their classmate not believing in God. Another occasion described by a teacher was during the lead-up to the recent equal marriage referendum in 2015, where a child repeated parental beliefs on homosexuality.

Over the course of the interviews however, the concrete ways schools ensure their ethos, or the ways the ethos is interpreted, differed throughout the 11 schools. In particular this was found in the delivery of the GMGY programme, and the approaches to sacramental preparation.

\subsection{Approaches to religious education: Goodness Me! Goodness You! (GMGY)}

Half of principals either 'agreed or strongly agreed' that RE (delivered through GMGY) was an important part of the school ethos. The junior programme (ages $4-9$ ) is largely delivered through stories on themes such as 'homes' or 'family' while the newly implemented senior curriculum covers four strands: Story, We are a Community National School; Thinking Time; and Beliefs and Religions. As this final strand is only one of four, the GMGY senior curriculum can be more accurately described as a values and ethics curriculum rather than purely religious.

The junior programme was originally delivered through two elements: a core element and a beliefspecific teaching (BST) element. The core element accounted for $80 \%$ of the allocated time for patron's 
programmes a year ( 25 minutes a day/ 1 hour a week). For the remaining $20 \%$ of the year (equating to 3-4 weeks), BST separated children into one of four beliefs groups, Catholic, Other Christian, Muslim and Other (also referred to throughout the schools as Hindu-Buddhist-Humanist or HBH). BST is no longer practised in nine out of 11 case study schools and the whole junior GMGY programme, which has attracted negative press attention for the separation of children by religion, has been under review since September 2017.

The BST element of the junior programme was a cause of concern for teachers and principals, expressed in both questionnaires and follow-up interviews:

It would be nice if there was a programme which was fully inclusive and respectful of all religions and beliefs. The senior programme for GMGY is meeting this criterion, but the junior end of the programme needs to be reviewed. (Questionnaire response)<smiles>[AlH2]</smiles>

At the end of those specific lessons the children were coming back and there was no engagement at the whole class level. It was like putting like-minded people who believe in the same thing into the same room, having a chat about yourselves and then coming back and that's it. Where is the learning? Where is the value in that? That's why we decided in this school to disengage with belief-specific teaching. (Kieran, Principal, U)

During our research, two schools were continuing with BST, although the majority of teachers and principals considered it inequitable. They also shared concerns over how to teach another's faith and some expressed being uncomfortable with teaching religion as 'truth' when they were of no faith. The logistics of splitting children up into different groups, the lack of resources (e.g. teachers and space), and the media criticism received, were also cited as reasons for suspending the programme: 
$[\mathrm{BST}]$ is the one thing that is bringing negative attention to our schools; what they are not seeing is all the positives. ... It's hardly a day's work in the whole year and yet one day's work in the whole year is causing nothing but negativity and I have to question the value of it. (Catriona, Principal, U)

The principals of the two schools that have continued with BST felt it worked; it was an easy way to nurture beliefs and was empowering for children to meet co-religionists from other classes:

[There were three young senior infant Muslim boys and they] found that they had Islam in common and they were brought out and they took part in the Muslim lessons and they were so excited when they came back to class. After that there were lessons then in the core part of the curriculum and they referred to elements of Islam and the three boys were empowered and strengthened to talk about it and share it. (Daithi, Principal, U)

These findings highlight the internal conflict staff in CNS feel towards living out their ethos, to provide belief-nurturing for all children as well as treating all children with respect. It is expected once the junior review is completed, a more united approach to the junior GMGY programme will be implemented throughout the school model.

The senior curriculum does not involve separating children into different groups. The belief-nurturing approach is met through a 'family project' where children are encouraged to complete a task with their parents that expressed their home beliefs:

They learn about [a topic] from all the different points of view, world views, and then they have a home project, they do their project at home and see how their family would celebrate 
it and they say 'well what does my family believe' and they bring it back in and they share the project with their class (Ethna, Teacher, $\mathrm{U})$

There was a notable difference between urban and rural schools in their delivery of the GMGY senior curriculum. In the below quotes, Josephine, teaching in an urban school near Dublin, drew on contacts she had and possessed confidence in delivering the programme. Ethan, teaching at a rural school, on the other hand, while innovative in integrating the other strands into his lessons, lacked confidence in delivering the Beliefs and Religions strand of the curriculum:

We made St. Brigid's crosses this year - that's something you'd only ever see in a Catholic school. We've looked at everything else as it's happened so why shy away from this? I had the Christmas trees, I had them make Rangoli mats, during Diwali I had a skype conversation with my cousin's husband who is Hindu, and he was answering their questions, so why shy away from other things? I think everything should be celebrated and I think you should see that when you come into the school (Josephine, Teacher, U)

$[\ldots]$

I wasn't sure if I had to deliver a certain aspect of the religion, and I knew nothing about the religion and I was wondering how am I actually going to teach this lesson when I know nothing about [it], so I wasn't sure what approach I was going to take. I wanted to wait and find out more about it and just get a bit of advice (Ethan, Teacher, R)

Ethan's reluctance stemmed from the lack of children in the school who came from different religious backgrounds, so he had little support to draw on like Josephine. While the senior curriculum is praised by teachers and enjoyed by the pupils, considering the differences between rural and urban schools, there may be a need for a more proactive approach (and perhaps additional support) for teachers 
delivering the Beliefs and Religions strand in less diverse classrooms to ensure all children at CNS have the same level of knowledge about diverse religions in an increasingly multi-belief Ireland.

\subsection{Sacramental preparation: equality of opportunity?}

While CNS do not aim to provide religious instruction, they offer sacramental preparation for Catholic pupils. Lessons for communion in second class and confirmation in sixth class are often provided during the school day, similar to Catholic schools. The type and duration of preparation offered differs in each school and is negotiated between CNS and individual parishes. Providing for sacramental preparation inside school hours in Irish schools has received criticism due to the separation of children on the basis of religion (Educate Together 2011).

The CNS model sees parents in a role as 'partner' of their child's education. While teachers and principals emphasised that parents were the primary educators of their child's faith, the role taken by parents and parish in preparing Catholic children for the sacraments is uneven throughout the schools. In some schools, parents and parishes are expected to take on more of a role and in one school preparation is undertaken completely outside of the school day. Some schools however, seem to take on the role themselves, although teachers suggested it was less than what is offered at a Catholic school:

We're quite good at drawing the line where we see our role - and as I say to parents, 'look you made a decision that you were raising your child in the Catholic faith when you had your child baptised, therefore you have role and responsibility to attend Mass regularly, to explain to your child what it means to be a Catholic, to raise them in that faith'. (Dervla, Principal, U) 
Schools have differing levels of involvement for sacramental preparation during the school day. Children are often removed from GMGY time for 30 minutes a week during certain times of the year to prepare for their sacraments. This presents a challenge for the model with meeting its ethos of inclusivity. It assists in 'othering' of children, highlighting Catholic children as a group deserving of more attention within the school day. Teachers expressed concerns over the perceived privileging of Catholic pupils, something minority-faith pupils also noted:

Dana: Some groups [do religion classes] more often.

Interviewer: Which groups?

Shannon: I suppose the Catholics...

Dana: Yeah, the Catholics do it more often

(Pupils, Christian, R)

One way schools aimed to reconcile the challenges this poses to their ethos was through an 'equality of opportunity' approach; a conscious effort to offer support for faith formation or preparation of rites of passage by request of families and parents of all faiths. Most schools however reported that minority-faith families did not take this up:

It's part of our ethos, it's part of us as a community national school to help prepare the children for sacramental preparation. I know the debate could be what about if other children, other religions or beliefs, want us to prepare them - but we haven't come across that yet. We haven't been asked to do it yet. (Katie, Teacher, U)

In our research we found many minority-faith children attended after-school classes, independent of the CNS, for religion and language lessons, therefore reducing their dependence on school as a site 
for this learning. Minority-faith parents have been found to often take on a more proactive role in their child's faith formation than Irish parents (Darmody et al. 2016). At the time of interviewing, only Catholic families had made requests for religious instruction in the form of sacramental preparation. While many schools describe their ethos as offering faith formation to all beliefs, in practice, only one belief group is supported in this way.

While many teachers suggested sacramental preparation was inequitable, they also expressed frustration that without this, CNS may reduce their white, Irish Catholic families, and through doing so, lose the reflection of the local community in their school:

My personal opinion is that one of the reasons that [providing sacramental preparation in the school day] was left into the community national school model was to actually attract Irish parents to the model because what you would have if that was taken out you will have parents in a position not to send their Irish child to that school and they will send them to a Catholic school instead and you will end up in a community like [here], even though it's so diverse, you will have $100 \%$ white Irish in the Catholic school and you would have $100 \%$ nonethnic Irish [in another school]. (Joanne, Teacher, U)

Many teachers stated it was important to their ethos to reflect the local community they were in, as part of a wider commitment to reflecting a modern diverse Ireland. Treading this delicate balance between maintaining a diverse and reflective school community as well as acknowledging a cultural practice of Catholic families, is arguably a challenge for the CNS model.

Teachers also raised concerns about the Catholic Church's control over education in Ireland. As a new state-run model of education aiming to be multi-denominational, teachers expressed a feeling of being stuck in the middle, trying to accommodate for increasing diversity while still operating within 
a heavily traditional system. Ryan, the principal at a newer school with only infant classes, described the CNS approach to sacramental preparation as 'an Irish solution to an Irish problem', indicating Ireland's unique situation of faith formation during the school day compared to the rest of Europe. Traditionally, schools in Ireland were the primary sites of Catholic faith formation with schools providing the bulk of sacramental preparation. The majority of teachers reported that when talking to new families, they are often asked by Catholic parents' whether the sacraments can be provided for by the school. They suggested the multi-denominational model with its limited emphasis on faith formation appealed to parents, who nevertheless wished for their child to receive sacraments. This may be a reflection of a traditional practice for Catholic children, rather than a reflection of a family's religiosity:

Even though they wanted something broader [multi-denominational education] for their children, they also wanted this Holy Communion piece. They didn't necessarily want religious education in the Catholic faith for junior, first and second [class], it was more the sacraments they were interested in rather than faith formation. (Sean, Teacher, U)

The approach taken to sacramental preparation in CNS is influenced by the relationship with the local parish. Joanne describes a bartering style system where she 'fought tooth and nail' for the school to provide seven hours preparation when the parish originally wanted 36 hours. Ryan's school has not started communion preparation yet; while he would ideally like to provide preparation outside of school hours, he recognises the role the parish will play:

I've heard [the parish priest] is quite young so I'm hoping he'll be reasonable, but I have heard horror stories from other CNS [sic] schools - [the parish] can be quite dictatorial; they want this, this is how it is, or [the children are] not getting their communion - and I'm really hoping to avoid something like that (Ryan, Principal, U) 
One school has an arrangement with the parish to undertake sacramental preparation outside school hours which is seen by many schools as the ideal standard. This school was able to arrange this due to the parish accommodating it alongside the local Educate Together (ET) school. Teachers and principals also acknowledge the stretched resources of some parishes, where there are not enough priests or laypeople to provide preparation outside school hours. Across all CNS schools, there is recognition of a need for standardising the approach to sacramental preparation. Many are in favour of sacramental preparation being provided for outside the school day however, and many principals wished to see parents and parishes taking on more responsibility. The CNS approaches to RE and faith formation are evolving though and it is likely the model will develop a more standardised approach to this moving forward.

\subsection{Intercultural education: celebrating diversity and inclusion}

To meet their ethos of inclusion and to celebrate their diversity, many schools have an intercultural day where families bring in food from their home countries, dress in traditional garments or partake in performances. Most schools also featured wall art highlighting the variety of beliefs and nationalities present in their school with many incorporating a 'beliefs wall' featuring symbols from a variety of beliefs. Maps indicating the countries where their children's families came from were also common; this is not just about migrant families, as some of the Irish children had a parent from another country such as Germany, New Zealand or the USA.

Language was a particular way schools expressed their inclusive ethos. One school provided an afterschool language club for their Polish children. Many teachers explained they did not discourage children from speaking their home language, particularly if they were new to the school, and 
encouraged them to converse with other children with the same language in an effort to support their transition into the school:

One of the kids only said it to me today - we were coming out of the yard and she said [pointing to another child] "She's speaking in Polish" - [this was one] of my polish children who had just joined the class [said this] and I was like "That's okay, she can speak in Polish", and [the child said] "In my old school I could never speak Polish". I think it's really important that they're allowed to speak their own tongue because that's what they're speaking at home. (Tara, Principal, R)

Language support was given to new pupils and classrooms often had examples of words from the different languages spoken in the school. With Irish schools having Irish (Gaelige) as a compulsory subject, some migrant children speak upwards of three languages, including English, Irish and perhaps one or two 'home' languages. Interestingly, one school teaches Mandarin Chinese as a compulsory subject in addition to Irish. The premise for this was the ability for younger children to learn foreign languages. While this was the only school to have such as initiative, multilingualism found support throughout all schools and pupils commented on enjoyment of learning new words from their friends:

The girl I used to be best friend's with [until she went to another school] was Muslim, she was from Pakistan and she would teach me words in her language and I would teach her words in my language and then every time we meet we would say 'hi' to each other in each other's language. (Geeta, Pupil, Hindu, U)

The support given to multilingualism is in contrast to findings from other studies which found native language speaking to be discouraged in Irish schools (Darmody 2011). While the emphasis in this study is on religion and beliefs, this unexpected finding highlights language as an important part of migrant 
children's identity and may be an interesting avenue for further research on CNS. The promotion of mother-tongue language is also a useful way of respecting diversity as advised by EU recommendations (European Commission 2008) which is mirrored in the CNS model and is a particularly interesting way they practise an ethos of inclusivity.

Interviews with school staff highlighted many ways schools attempted to practice an inclusive ethos. Dervla (Principal) gave the example of parents coming up with an inclusive alternative to Halloween which they recognised may exclude children from certain religious backgrounds:

They call it our autumn fun day and children are welcome to dress up or come in non-uniform or come in their uniform, whatever they feel most comfortable with. And there was just this whole conversation [between parents] and because of the way [they] talked about it, rather than 'no my children can't participate' it was 'how can we involve everybody in our school activities so that it is accessible to all' and we noticed that the year we did it that way, the previous year it had been called Halloween, there was an increase in our attendance (Dervla, Principal, U)

Teachers also shared ways they dealt with religious differences in the classroom at the request of parents. One teacher described a 'tricky' situation where a mother had told her Father Christmas does not come to their house. The teacher did not want to exclude the child from the class discussions at Christmas, but also wanted to recognise her particular faith (Bahá'í) and respect the mother's wishes:

So we just went with "Santa comes to some people's houses and doesn't come to other people's houses" [laughs] I know - and "Santa comes to Evie later on in the year". They're only junior infants and they were all like oh yea [in agreement] (Lottie, Teacher, $\mathrm{U}$ ) 
While faith formation is not part of the approach of CNS, many schools attempted to facilitate parental requests such as excusing children from some activities (e.g. swimming). The hijab is also permitted, with the requirement that it is black or the colours of the school uniform, in line with many other Irish schools (Honohan and Rougier 2011). Daithi explains that inclusion is met in his school by not excluding anyone:

That's how we live out our inclusive ethos, by not excluding and nobody feels excluded. And if they do feel excluded we will work on that, and we will learn from that, but nobody intentionally feels excluded during a school day upon faith or denominational or nationality backgrounds, they're not excluded for any of those reasons from the school day. (Daithi, Principal, U)

Inclusion is approached in CNS though a reflective process guided by principles of respect, inclusion and equality, and adapted to suit the needs of each school's community. The Department of Education describes a strong sense of social cohesion in school being based on the 'quality of relationships' between actors in the school, such as the ways 'pupils and teachers treat each other' (Department of Education 1991). The evidence from CNS illustrates efforts made by school staff to accommodate needs of their diverse population and being sensitive to and recognising differences. Bryan and Bracken (2011) warn against excluding students own experiences in intercultural education. The reflective approach of the CNS model encourages dialogue between children. Rather than relying on textbooks, a variety of resources are drawn upon including children's own stories, and engagement with parents and faith leaders.

While differences were noted in our research between rural and urban schools in their approaches to RE and teaching other faiths, Tara explains that the model's overall emphasis on equality and inclusion is as much part of the rural environment as it is in the city: 
One part of [the CNS model and ethos] is that everyone is welcome but that also leads itself towards every type of family so making sure that we cover - I suppose not wrapped up in a Catholic ethos - having books where there are two gay parents or having books where there is a single mum or having books around the school where everybody feels like they belong. I think that's really important and I don't think that's any more - I think that's needed [here] as well as in [Dublin] as well as anywhere else (Tara, Principal, R)

While the main focus of this study was RE, many teachers and principals stressed that religion was only one 'ingredient' in their schools. It was part of the school atmosphere, but not the most important part, although recognition and acceptance of the multi-belief nature of the schools helped them live out their ethos of inclusion.

\section{Conclusions}

Ethos is a contested concept in the literature (Furlong 2000), however, it remains important for understanding the general processes in schools, as well as their values and traditions. Education has often been turned to as a way of promoting social cohesion, and an official ethos, such as 'integrated' (e.g. Northern Ireland), or the CNS model of 'multi-denominational' in Ireland can help promote a school identity (see Bragg and Manchester 2011). This not only provides parents with a vision of the type of education that will be received, but also guides school staff in their everyday practice. Elsewhere in Europe, Norwegian schools promote inclusion through an ethos rooted in Christian ideology, but also draws upon Humanism, to foster respect for all beliefs (Williams 2016). In Northern Ireland, a small number of 'integrated schools' have been set up promoting an ethos whereby pupils and teachers engage with difference and upholding respect for all beliefs and none (Hansson, O'Connor Bones and McCord 2013). These schools primarily maintain an ethos of integration through 
ensuring a balanced intake of students from all backgrounds. However, there is little consensus on the model of integration that should be used in Northern Ireland, and schools vary in their approaches (Montgomery et al. 2003).

The concept of institutional habitus (Reay et al. 2001) was introduced alongside ethos as a potential way to understand how particular educational institutions can influence an individual's experience of school. This article presents a school model evolving in its approach and growing into its ethos. How ethos impacts on how the school influences and instils values of inclusivity and equality in its pupils and staff is yet to be seen. As the model matures, and pupils move on to secondary and tertiary education, the effects of attending a CNS would be an interesting future avenue of research.

While all the CNS promote an inclusive and equal ethos, and each school attempts to live out this ethos through their everyday practice, some aspects of the model differ throughout the 11 schools in our study. Differences were found in the approach to delivering the GMGY curriculum, particularly between urban and rural schools, and in sacramental preparation for Catholic children. The lack of a standardised approach to sacramental preparation can obscure an over-arching CNS identity. The practice of preparing children for the sacraments during the school day can be seen as privileging the Catholic faith over others, presenting a challenge to this ethos and may serve to actively weaken claims to inclusivity and equality. The 'equality of opportunity' approach taken by schools, where all families are offered support for religious instruction or rites of passage, overlooks the fact that many minorityfaith families take a more proactive approach to their child's faith formation through after-school lessons and participating in their faith community (Darmody et al. 2016).

Sacramental preparation for Catholic children in primary schools is as much a cultural practice as it is religious. Due to a long history of Irish primary schools as sites of faith formation, it may be a difficult element to reconcile for CNS who desire to accommodate for all those in their community, Catholic 
and non-Catholic alike. To be truly inclusive, the approach to sacramental preparation may need to be revised. This has been recognised by the model's patrons, the ETB, and there are moves towards standardising the approach and moving sacramental preparation to outside the school day $\left(\mathrm{O}^{\prime}\right.$ Brien 2017). From a wider perspective, however, attitudes towards what is increasingly a 'cultural' practice may also need to shift within the community.

The multi-denominational ethos of the CNS guides school staff in accommodating the diversity in their schools. The long-lasting impact the school ethos has on its pupils remains to be seen, however, and will be an interesting area to follow up in time. We found a school model recognising and understanding its ethos as multi-denominational, and taking active steps to accommodate all faiths and beliefs equally. Recognition and celebration of diversity was woven throughout the everyday life of the CNS, in varying degrees. Despite differences, however, the schools share many practices such as non-discriminatory admission policies, a multi-belief RE programme, intercultural events and an encouragement of children's multilingualism. These all assist CNS to live out their inclusive and equal ethos. The discontinuation of belief-specific teaching in most schools is also recognition that the original stipulation of separate RE classes may not be an equitable practice. This illustrates a school ethos that is evolving. The concrete ways this is practised vary between schools and so may require a more standard approach to be developed to assist in promoting an over-arching CNS identity.

\section{Notes}

1. Many schools tend to be over-subscribed and names need to be put down when the child is born to ensure a place in a specific school. It is expected the new School Admissions Bill (2016) makes the enrolment process more equitable.

2. ETBI (Education and Training Boards Ireland) 'Community National Schools: Welcome to the Schools of the Future' Leaflet, distributed 2016. 


\section{References}

Avram, S. and J. Dronkers. 2013. Religion and schooling: the European context', in E. Smyth, M. Lyons and M. Darmody (eds) Religious Education in a Multicultural Europe: Children, Parents and Schools. Basingstoke Palgrave.

Bragg, S. and H. Manchester. 2011. Creativity, school ethos and the creative partnership programme. Final Report of the project: Evaluation of the nature and impact of the Creative Partnerships programme on school ethos 2009-10. The Open University.

Breen, D. 2009. "Religious diversity, inter-ethnic relations and the Catholic school: introducing the responsive approach to single faith schooling." British Journal of Religious Education 31 (2): 103-115.

Breen, M.J. and C. Reynolds. 2011. "The rise of secularism and the decline of religiosity in Ireland: the pattern of religious change in Europe." The International Journal of Religion and Spirituality 1 (2): 195-212.

Bryan, A. and M. Bracken. 2011. "'They think the book is right and I am wrong': Intercultural education and the positioning of ethnic minority pupils in the formal and informal curriculum." In Changing Faces of Ireland: Exploring Lives of Immigrant and Ethnic Minority Children, edited by Merike Darmody, Naomi Tyrrell and Steve Song, 105-124 Rotterdam: Sense.

Bourdieu, P. 1993. Sociology in Question. London: Sage.

Bourdieu, P. and J.C. Passeron. 1977. Reproduction in Education, Society and Culture. Beverly Hills, CA: Sage.

Central Statistics Office (CSO) 2017. Census 2016 Summary Results - Part 1. Dublin: CSO. 
Cohen-Zada, D. 2006. "Preserving religious identity through education: Economic analysis and evidence from the US". Journal of Urban Economics 60 (3): 372-398.

Darmody, M. 2011. "Power, education and migration into Ireland". Power and Education 3(3): 224237.

Darmody, M., M. Lyons and E. Smyth 2016. "The home-school interface in religious and moral formation: the Irish case." British Journal of Religious Education 38: 1-15.

Darmody, M., and E. Smyth 2017. Education about Religions and Beliefs (ERB) and Ethics: Views of Teachers, Parents and the general public regarding the proposed curriculum for primary schools - consultation paper. Dublin.

Darmody, M., E. Smyth and S. McCoy 2012. School Sector Variation among Primary Schools in Ireland. Dublin: Economic and Social Research Institute.

Department of Education 1991. Circular M33/91 - Guidelines towards a positive policy for school behaviour and discipline. Dublin: Department of Education.

Donnelly, C. 1999. "Differences in Schools: a question of ethos?" Paper presented at the British Educational Research Association Annual Conference, University of Sussex, September 2-5.

Educate Together 2011. A Report on the Transition to Faith Formation Outside School Hours in Early Educate Together Schools. Educate Together.

European Commission. 2008. "Migration and mobility: challenges and opportunities for EU education systems," COM(2008) 423.

Faas, D. 2007. "Turkish youth in the European knowledge economy: an exploration of their responses to Europe and the role of social class and school dynamics for their identities". European Societies 9(4): 573-599. 
Faas, D. 2010. Negotiating Political Identities: Multiethnic Schools and Youth in Europe. London: Routledge.

Faas, D., M. Darmody and B. Sokolowska 2016. "Religious diversity in primary schools: reflections from the Republic of Ireland". British Journal of Religious Education 38(1): 83-98.

Faas, D., A. Smith and M. Darmody 2018. "The role of principals in creating inclusive school environments: insights from community national schools in Ireland". School Leadership \& Management (Online First: DOI: 10.1080/13632434.2018.1430688).

Ferrari, S. and S. Pastorelli. 2010. "The public space: The formal and substantive neutrality of the public sphere." RELIGARE Working Paper No. 4. www.religareproject.eu (accessed 4 December 2017).

Furlong, C. 2000. "Comprehending Culture-School Organisation, a Cultural Perspective" in School Culture and Ethos: Cracking the Code edited by Catherine Furlong and Luke Monahan, Marino Institute of Education, 2000.

Hansson, U., U. O'Connor Bones and J. McCord. 2013. Integrated Education: A Review of Policy and Research Evidence, 1999-2012. University of Ulster.

Hemming, P.J. 2011. "Meaningful encounters? Religion and social cohesion in the English primary school." Social \& Cultural Geography 12(1): 63-81.

Hargreaves, D.H. and D. Hopkins. 1991. The Empowered School. London: Cassell.

Honohan, I. and N. Rougier. 2011. The embodiment of tolerance in discourses and practices addressing cultural diversity in Irish schools. San Domenico di Fiesole: European University Institute Robert Schuman Centre for Advanced Studies.

McGovern, F. and D. Devine 2016. "The care worlds of migrant children: Exploring inter-generational dynamics of love, care and solidarity across home and school." Childhood 23(1): 37-52. 
McLaughlin, T. 2005. "The Educative importance of ethos." British Journal of Educational Studies 53 (3): 306-325.

McKinney, S.J. 2011. 'Communicating Faith through religious education', in J. Sullivan (ed.) Communicating Faith, Washington: The Catholic University of America Press.

Monahan, L. 2000. "School Culture and Ethos-Partners for the New Millennium" in School Culture and Ethos: Cracking the Code edited by Catherine Furlong and Luke Monahan, Marino Institute of Education.

Montgomery, A., G. Fraser, C. McGlynn, A. Smith and T. Gallagher. 2003. Integrated Education in Northern Ireland: Integration in Practice, University of Ulster: UNESCO Centre.

Munn, P. 2008. "Ethos and Discipline in the Secondary School." In Scottish Education edited by Tom Bryce and Walter Humes, Edinburgh: Edinburgh University Press.

O'Brien, C. 2017. "State-run primary schools to drop faith formation in class time". September 22 2017. https://www.irishtimes.com/news/education/state-run-primary-schools-to-drop-faithformation-in-class-time-1.3229605 (accessed 4 December 2017).

O’Toole, B. 2015. "1831-2014 : an opportunity to get it right this time? Some thoughts on the current debate on patronage and religious education in Irish primary schools". Irish Educational Studies 34(1): 89-102.

Reay, D., M. David and S. Ball. 2001. "Making a Difference?: Institutional Habituses and Higher Education Choice." Sociological Research Online 5 (4).

Sai, Y. 2018. "An exploration of ethos in Irish Muslim schools: ethnographic insights and perspectives from parents and teachers." Journal of Beliefs \& Values 39(1): 29-44. 
Smyth, E. and M. Darmody. 2011. "Religious Diversity and Schooling in Ireland" in Changing Faces of Ireland: Exploring Lives of Immigrant and Ethnic minority Children edited by Merike Darmody, Naomi Tyrrell and Steve Song, 125-144, Rotterdam: Sense.

Smyth, E., M. Lyons and M. Darmody. eds. 2013. Religious Education in a Multicultural Europe: Children, Parents and Schools. Basingstoke: Palgrave Macmillan.

Wilson, H.F. 2014. "Multicultural learning: Parent encounters with difference in a Birmingham primary school." Transactions of the Institute of British Geographers 39 (1): 102-114. 